\title{
A STUDY ON THE SHORT TERM EFFECTS OF GRID LASER PHOTOCOAGULATION AND COMBINATION TREATMENT (GRID LASER WITH INTRAVITREAL BEVACIZUMAB) IN THE MANAGEMENT OF DIABETIC MACULAR OEDEMA
}

\author{
Adil Agarwal1, Mary Thomas², Allen Shankar R33, Shantha Sruthi M4 \\ ${ }^{1}$ Consultant Vitreoretinal Surgeon, Department of Ophthalmology, Agarwal's Eye Hospital, Chennai. \\ ${ }^{2}$ Associate Professor, Department of Ophthalmology, Sri Ramachandra Medical College \& Research Institute, Porur, Chennai. \\ ${ }_{3}^{3}$ Post Graduate Student, Department of Ophthalmology, Sri Ramachandra Medical College \& Research Institute, Porur, Chennai. \\ ${ }^{4}$ Post Graduate Student, Department of Ophthalmology, Sri Ramachandra Medical College \& Research Institute, Porur, Chennai.
}

\section{ABSTRACT}

\section{AIM}

To study the short term effect of grid laser photocoagulation in the treatment of diabetic macular oedema. As a comparison, the short term efficacy of combination treatment of grid laser photocoagulation along with intravitreal injection of bevacizumab was studied in the treatment of Diabetic Macular Oedema (DME).

\section{MATERIALS AND METHODS}

74 eyes of 43 patients between the ages of 50-60 years with diabetic maculopathy were selected. These patients were then assigned to either groups of standalone photocoagulation therapy (Group I) or combined therapy of photocoagulation with intravitreal Avastin (Group 2). Best Corrected Visual Acuity and Optical Coherence Tomography findings were done in all the patients during a follow-up done every four weeks up to twelve weeks.

\section{RESULTS}

In Group I, at the end of 12 weeks, overall 34\% patients showed an improvement or stability in visual acuity. $66 \%$ of the patients had a decrease in visual acuity. The number of eyes with decline in visual acuity decreased during 4 to 12 weeks. $59.22 \%$ of the eyes showed improvement or stability in the visual acuity in Group 2. The mean central macular thickness remained stable or increased in $70.2 \%$ of the eyes, whereas the CMT decreased only in $29.8 \%$ eyes. But in Group 2, at the end of 12 weeks, $59.3 \%$ had a decrease in CMT. Total Macular Volume (TMV) in Group I, decreased in 57.4\% of the eyes. On the other hand, in Group 2 at 12 weeks, 59.3\% showed a decrease in TMV, which is slightly better than in Group 1.

\section{CONCLUSION}

The patients with DME who underwent combined photocoagulation with intravitreal injection of Avastin showed significant improvement in visual acuity, central macular thickness and macular volume as compared to the patients who underwent standalone laser photocoagulation, though neither of the groups showed completely satisfactory improvement. Study with large number of patients and long term follow-up would be considered ideal.

\section{KEYWORDS}

Laser Photocoagulation, Intravitreal Avastin Injection, Combined Therapy, Diabetic Macular Oedema.

HOW TO CITE THIS ARTICLE: Agarwal A, Thomas M, Allen Shankar R, et al. A study on the short term effects of grid laser photocoagulation and combination treatment (Grid laser with intravitreal bevacizumab) in the management of diabetic macular oedema. J. Evolution Med. Dent. Sci. 2016;5(36):2147-2153, DOI: 10.14260/jemds/2016/501

\section{INTRODUCTION}

Diabetic retinopathy (DR) is the damage caused to the micro vascular system in the retina due to prolonged hyperglycaemia in both type I and Type II Diabetes Mellitus. Type II diabetes was seen to frequently cause diabetic macular oedema (DMO) in older patients and less commonly it lead to proliferative diabetic retinopathy.(1) The systemic risk factors for DR include increased duration of diabetes, old age, associated systemic hypertension, pregnancy and poor control of diabetes.

Financial or Other, Competing Interest: None.

Submission 21-03-2016, Peer Review 15-04-2016,

Acceptance 21-04-2016, Published 05-05-2016.

Corresponding Author:

Dr. Mary Thomas,

Associate Professor

Department of Ophthalmology,

Sri Ramachandra Medical College \& Research Institute,

Porur, Chennai-600116,

Tamilnadu,

India.

E-mail: marysanthoshj@yahoo.co.in

DOI: $10.14260 /$ jemds/2016/501
The ocular factors protective against DR are myopia, glaucoma and retino-choroidal scarring resulting from trauma and inflammation.

In diabetic patients leading cause of defective vision is diabetic maculopathy. $(2,3)$ The pathogenesis being impairment of Blood-Retinal-Barrier (BRB) resulting from disruption of the tight junctions between the retinal endothelial cells and changes in the retinal capillaries leading to accumulation of fluid and protein in the intraretinal layers of macula, which distorts central vision.(4) Many ocular diseases including diabetic retinopathy, vascular occlusions, postsurgical conditions and uveitic diseases lead to the development of macular oedema. Inflammatory processes leading to an increase in vascular permeability play the important role. Mediators like Angiotensin II, prostaglandins and the Vascular Endothelial Growth Factor (VEGF) take part in the inflammation.(5)

In the Early Treatment Diabetic Retinopathy Study (ETDRS), laser photocoagulation has proven to be effective in the reduction of visual morbidity for all eyes with (DME).(6,7) Laser photocoagulation has been the gold standard of 
treatment, though the visual outcomes in these patients have not always been sufficient.(7)

The importance of Vascular Endothelial Growth Factor (VEGF) in promoting vascular permeability and transition of fluid from intracellular to extracellular compartments has been stressed upon by many researchers.(8,9) The use of AntiVEGF agents have found to be effective in the treatment of DME. Bevacizumab is a recombinant humanized monoclonal IgG1 antibody that binds to all VEGF isoforms and inhibits action. It is available commercially as Avastin (Genentech, South San Francisco, CA).(10-12) Bevacizumab binds to soluble VEGF and inhibits the binding of VEGF molecules to its receptors on the surface of endothelial cells. Bevacizumab is a nonspecific VEGF inhibitor with two binding sites per molecule. Bevacizumab prevents all VEGF-A isoforms from binding to endothelial cell receptors.(13-16) Reduction in activity of VEGF inhibits angiogenesis and vascular permeability.

Avastin is preferred over other anti-VEGF agents (Though it is an off label use) due to its cost-efficiency. The efficacy of intravitreal injection of anti-VEGF agents have been credited by several studies. Pharmacological intervention furthermore has the added advantage of ease of administration and early benefit to the patient. However, the short half-life of anti VEGF agents warrants multiple injections in these patients, as is proved in the current study.

\section{AIM}

A Prospective Non-Randomized Interventional Cohort Study was conducted to Study

1. The efficacy of grid laser photocoagulation in the treatment of DME

2. The short term efficacy of combination treatment (grid laser photocoagulation plus intra vitreal bevacizumab) in the treatment of DME.

3. To address any safety concerns with the use of intra vitreal Bevacizumab.

In view of a larger picture, the main aim of this study was to find the ideal method of treatment of diabetic maculopathy in a cost effective setting.

\section{MATERIALS AND METHODS}

This prospective study was conducted in the setting of a Multispecialty Hospital in a Medical College over a period of three years. Seventy-four eyes of forty-three patients with diabetic maculopathy who were either detected or referred to this tertiary care centre from elsewhere were enrolled for this study.

As a criterion, all the patients included in the study were to have a confirmed diagnosis of diabetic retinopathy with a supportive clinical and angiographic evidence of diffuse or focal macular oedema. Patients who were found to have coexisting eye diseases that could also be a cause of visual impairment did not qualify to be included in the study.

The exclusion criterion included (1) Amblyopia due to any cause, (2) Glaucoma (3) Non-diabetic maculopathy (4) Ischaemic maculopathy as shown by Fundus Fluorescein Angiography (FFA), (5) Vitreous haemorrhage and active proliferative diabetic retinopathy during the selection of study subjects, (6) Bio-microscopic evidence of vitreomacular traction as seen in epiretinal membrane or vitreoretinal traction as seen in proliferative diabetic retinopathy.
All the enrolled patients were subjected to an initial clinical evaluation including a detailed history with emphasis on the diabetic age and glycaemic control and the presence of other comorbid illness such as hypertension, tuberculosis, bronchial asthma and any other illness that could cause ocular morbidity. The subjects also had blood investigations done to document presence of associated systemic risk factors like anaemia, hypertension, hypercholesterolemia and nephropathy. Snellen's chart was used to record the Best Corrected Visual Acuity (BCVA) and a slit lamp examination was done for all patients considered for the study. Intraocular Pressure (IOP) of all patients were recorded using Goldmann applanation tonometer. Fundus examination was done using slit lamp biomicroscopy with a +78 D lens and indirect ophthalmoscopy with the use of a +20 D lens. Optical Coherence Tomography (OCT) imaging (Spectral domain OCTCarl Zeiss 450 plus) was done to further study the retinal characteristics using 6 diagonal slow $6 \mathrm{~mm}$ radial lines through a dilated pupil.

The thickness of the $1 \mathrm{~mm}$ central macula was obtained using the macular thickness map. The type of DME on OCT was noted. FFA was done (5ML 10\% concentration sodium fluorescein) to detect the maculopathy and to classify the macular oedema into (1) Focal oedema, where a cluster of leaking micro aneurysms lead to hard exudates and fluid within the macula, (2) Diffuse oedema, where diffuse leakage from the vessels and defective RPE pumping mechanism is presumed to be responsible for fluid collection, (3) Ischemic maculopathy where there is macular capillary non-perfusion, and (4) Mixed maculopathy.

On the basis of the ETDRS criteria, the patients were classified in terms of the severity of diabetic retinopathy and the type of maculopathy. These patients were then randomly assigned to either groups of standalone photocoagulation therapy or combined therapy.

The subjects in Group I were treated with grid laser photocoagulation using the IRIDIS laser machine. The laser photocoagulation was done by dedicated retina specialist, who performs the procedures routinely, using the Argon green laser. The ETDRS protocol was followed for the laser photocoagulation. The subjects in the Group 2 underwent intravitreal injection of Anti-VEGF agent Bevacizumab (AVASTIN) $1.25 \mathrm{mg}$ in $0.05 \mathrm{ml}$ under strict aseptic precautions with pre-injection and post-injection cover of topical antibiotic.

The grid laser treatment was performed a week after the intravitreal injection. The subjects in both groups were seen in the follow-up reviews at 4, 8 and 12 weeks. Visual acuity, intraocular pressure and OCT to measure the Central Macular Thickness (CMT) and Total Macular Volume (TMV) were done on each visit.

\section{RESULTS}

74 eyes of 43 patients were enrolled in our study; 47 were allotted to Group I and 27 were allotted to Group 2. In Group $1,64.4 \%$ were in the 50 to 70 years' category. The mean age of the patients who participated in the study was 59.71 years. None of the patients included in our study were below 46 years of age [Table I and 2]. In Group I, the male: female ratio was approximately 1.3:1. Among the patients in this group, $63.83 \%$ had a visual acuity of $6 / 12$ or better on presentation. 
In Group 2 the, male: female ratio was approximately $1.2: 1$ and $51.8 \%$ of the patients had a visual acuity of $6 / 12$ or better on presentation [Table 3].

In all 74 eyes, the diffuse leak was the predominant finding seen on FFA. This trend was similarly seen in both treatment groups. In Group I, 57.4\% of the eyes had diffuse leak on FFA. In Group 2, 67\% of the eyes had a diffuse leak on FFA significantly higher than that in Group 1. OCT analysis revealed that most patients presented with a focal thickening. But an important observation made was that a significant percentage also had Cystoid Macular Oedema (CME), which was usually associated with poorer visual prognosis as compared to the eyes with focal or spongiform thickening. In Group 1, among the 47 eyes, focal thickening was predominant but only 8.5\% had cystoid macular oedema. In Group 2, 8 eyes (30\%) had CME. Here, the majority of the eyes (37\%) had spongiform thickening [Table 4].

In Group 1, at the end of 12 weeks overall 34\% patients showed improvement or stability in visual acuity; $66 \%$ of the patients had a decrease in visual acuity. The number of eyes with decline in visual acuity decreased during 4 to 12 weeks; $59.22 \%$ of the eyes showed improvement or stability in the visual acuity, whereas $40 \%$ of the eyes showed a decline in visual acuity in Group 2. A significant finding seen was that the percentage of eyes with improvement in visual acuity increased from $18.5 \%$ to $22.22 \%$ [Table 5].

The mean CMT for patients in Group 1 was 249 microns. At the end of 12 weeks, the mean CMT had increased to 267.94 microns. CMT remained stable or increased in $70.2 \%$ of the eyes, whereas the CMT decreased only in $29.8 \%$ eyes. But in Group 2, the mean CMT at presentation was 401.85 microns. This decreased to 343 microns at the end of 12 weeks. Overall, $59.3 \%$ had a decrease in CMT, which was promising [Table 6 and 7]. Total Macular Volume (TMV) in Group I had a mean of 10.11 micro litres on presentation, which decreased to 9.81 at the end of 12 weeks. The TMV decreased in $57.4 \%$ of the eyes in this group. On the other hand, TMV in Group 2 showed a mean of 11.87 on presentation. This further reduced to 11.23 at 12 weeks. Overall, $59.3 \%$ showed a decrease in TMV, which is slightly better than in Group I.

\section{DISCUSSION}

DME continues to be the paramount cause of visual impairment in diabetic patients. The visual impairment from untreated macular oedema often leads to legal blindness and has a significant detrimental effect on the quality of life. Data from the Wisconsin Epidemiologic Study of Diabetic Retinopathy estimate that after 15 years of known diabetes, the prevalence of DME is approximately $20 \%$ in patients with type I DM, $25 \%$ in patients with type 2 DM who are taking insulin and $14 \%$ in type $2 \mathrm{DM}$ who do not take insulin.(17)

We report our study in 74 consecutive eyes with DME seen in the tertiary care system over a duration of three years. Cases allotted to grid laser photocoagulation (Group I- 47 eyes) or a combination of intravitreal bevacizumab with grid laser photocoagulation (Group 2 - 27 eyes). All subjects were followed for a period of 12 weeks. In both groups, patients predominantly were in the age group of 50 to 60 years. The male-to-female ratio was around 1.3:1.

Visual acuity at presentation was $6 / 12$ or better in $64 \%$ of Group I, whereas only $52 \%$ of Group 2 eyes had the same. Fundus fluorescein angiography pattern analysis showed a diffuse leak in $57.4 \%$ of eyes in Group I as compared to $66.7 \%$ in Group 2. An analysis of the OCT patterns revealed Cystoid Macular Oedema (CME) in $6.38 \%$ of Group I eyes and in $29.63 \%$ of Group 2 eyes. Mean CMT in Group 1 pre-treatment was 249.34 microns and in Group 2 pre-treatment was 401 microns. Mean TMV in Group 1 was 10.11 micro liters and in group 2 was 11.86 micro liters.

A number of studies have shown that good baseline prelaser visual acuity is a good prognostic factor. In our study, the beneficial effect of treatment was demonstrated for the eyes with good initial visual acuity. Older age, poor pre laser visual acuity and large size of macular oedema had a poorer visual outcome following laser photocoagulation for Clinically Significant Macular Oedema (CSME). The ETDRS also found that visual prognosis was worse for those eyes with lower pretreatment visual acuity.

Eyes allotted to Group 2 had (1) Worse visual acuity at presentation, (2) Higher incidence of CME (3) Greater CMT and TMV. These findings reveal that eyes with a relatively poor visual prognosis were allotted to group 2 by the treating clinician. There is enough published literature to indicate that diabetic CME and serous macular detachment respond better to intra vitreal injection of anti-VEGF. However, three patients with CME in Group I declined to have injection into the eye and hence underwent standard laser photocoagulation as per ETDRS protocol.

We have followed the study definitions of ETDRS with respect to diagnosis and treatment of CSME. In Group I, 9 (19.1\%) of eyes showed improvement in vision, stabilization in $7(14.9 \%)$ and worsening in $31(66 \%)$ eyes at the end of week 12. In ETDRS, significant visual loss occurred in 5 and $7 \%$ of treated eyes after one and two years respectively. The criteria for significant visual loss were decrease in more than three lines.(18)

In United Kingdom Perspective Diabetes Study (UKPDS) among $40.5 \%$ of patients who showed decrease in visual acuity, $3 \%$ had significant visual loss in spite of laser treatment i.e. loss of more than two lines on the Snellen's chart. This is in contrast to Olk et al where the significant visual loss was $4 \%$ following similar study definitions as followed by the ETDRS.

In another study assessing the long term visual outcome of the modified grid laser photocoagulation for the diffuse DME by Lee et al.(19) it was seen that three years after initial grid treatment the visual acuity improved in $14.5 \%$, remained unchanged in $60.9 \%$ and worsened in $24.6 \%$ of the eyes.

The ETDRS found that the incidence of moderate visual loss in all eyes with DME was $5 \%$ at one year for patients treated with focal laser photocoagulation. This figure did not include those who experienced mild or severe visual loss with more than $50 \%$ of patients in ETDRS study having 20/40 or better vision to start with. Our finding of $66 \%$ included any level of visual loss. We have included all grades of severity in our study.

We suspect that visual loss in our patients with severe NPDR with CSME may be more due to progression of their diabetic retinopathy rather than lack of effectiveness of laser photocoagulation.

In another retrospective study presented by Chabi et al, approximately $24.5 \%$ showed improvement in visual acuity, $24.5 \%$ showed no change and $50.9 \%$ showed a decrease in visual acuity 12 months after treatment. The decrease in vision and increase in macular thickness noted is probably due to 
transient increase in macular oedema [Figure $1 \mathrm{~A}$ and $\mathrm{B}$ ], that can happen after grid laser treatment. This will subside over 3-4 months and could be due to the sterile subtle inflammation induced by laser in eyes where the blood retinal barrier is already weak.(20)

Visual acuity improved in $22.2 \%$ of eyes, stabilized in $37 \%$ of eyes and worsened in $40.74 \%$ of eyes in group 2 . The CMT interestingly decreased at the week 4 follow up visit continues to decrease up to $8^{\text {th }}$ week and then plateaus off by the $12^{\text {th }}$ week visit. We report the results of 27 eyes with diffuse DME treated with intravitreal bevacizumab followed by grid laser photocoagulation. Results revealed both anatomical and functional improvement [Figure $2 \mathrm{~A}$ and $\mathrm{B}$ ]. Our results show that bevacizumab was tolerated well and no systemic adverse effects were noticed during the study. Ocular tolerance was also high and no ocular inflammation was noted.

The capillary permeability seen in DME is secondary to the release of VEGF, primarily VEGF-A which is inhibited by the pan VEGF monoclonal antibody, Avastin. Clinicians worldwide have started using intra vitreal injections to treat DME either as a primary modality of treatment or when other standard treatment modalities like laser fail to achieve desired results. In a study by Haritoglou et al, intravitreal Avastin was used to treat DME (Wherein all patients had some form of previous treatment). They concluded that intra vitreal Avastin helps decrease macular oedema even when other treatments have failed.(21)

In another land mark study, the Pan American collaborative study group (PANCORES) studied the effect of primary intravitreal Avastin in diffuse macular oedema. At the end of two-year follow-up, the number of mean injections required was 5.8 with stability being documented in terms of BCVA and OCT at the end of 24 months.(22) In a similar study done by Atul Kumar et al, the effect of 2 injections of Avastin given 6 weeks apart was studied in patients with diffuse DME. These patients had undergone some form of laser therapy within 6 months before the first injection.(23)

In our study, the patients underwent laser photocoagulation one week after the intra vitreal Avastin (1.25 mg in $0.05 \mathrm{~mL}$ ). This is because intravitreal Avastin will decrease the bogginess at the macula by decreasing the vascular permeability especially in cases with CME and serous macular detachment. This not only makes photocoagulation easier, but also allows lesser power to be delivered to achieve milder burns. The other advantage of intravitreal Avastin before laser photocoagulation is that Avastin can theoretically decrease the transient increase in macular oedema induced by laser as intravitreal Avastin is documented to start acting within 48 hours after the injection.

An interesting finding noted during the study was that the decrease in CMT was quite significant at the $4^{\text {th }}$ week follow-up and continues up to the $8^{\text {th }}$ week after, which the effect plateaus off due to wearing off of Avastin. Hence, intravitreal Avastin is a valid primary treatment option for cases of DME where the macular oedema is diffuse or associated with cystoid spaces or serous detachment, not only in cases where the macular oedema has not responded desirably to other treatment modalities. Interestingly in a Phase II randomized trial done by Ingrid Scott et al to study the short term effect of intravitreal bevacizumab for DME showed that combining focal photocoagulation with bevacizumab resulted in no apparent short-term or adverse outcomes.(24)

Another randomized trial was done by Sohelian et al to compare the results of intravitreal bevacizumab injection alone or in combination with Intravitreal Triamcinolone Acetonide (IVT) versus Macular Laser Photocoagulation (MPC) as a primary treatment of DME. No adjunctive effect of IVT was demonstrated.(25)

\section{DRAWBACKS}

In our study there have been no serious adverse events or any other systemic safety concerns noted with intravitreal Avastin. However, since the follow up period was too short, no treatment recommendations can be made and further studies are warranted to find out the most ideal treatment for DME in the current scenario.

\begin{tabular}{|c|c|c|}
\hline Age & Frequency & Percent \\
\hline <49 years & 6 & 12.8 \\
\hline 50-59 years & 17 & 36.2 \\
\hline 60-69 years & 17 & 36.2 \\
\hline 70-79 years & 5 & 10.6 \\
\hline 80-89 years & 2 & 4.3 \\
\hline Total & $\mathbf{4 7}$ & $\mathbf{1 0 0 . 0}$ \\
\hline \multicolumn{2}{|c|}{ Table 1: Age Distribution in Group I } \\
\hline
\end{tabular}

\begin{tabular}{|c|c|c|}
\hline Age & Frequency & Valid Percentage \\
\hline$<49$ years & 2 & 7.4 \\
\hline $51-59$ years & 12 & 44.4 \\
\hline $60-69$ years & 11 & 40.7 \\
\hline $70-79$ years & 2 & 7.4 \\
\hline Total & 27 & 100.0 \\
\hline
\end{tabular}

\begin{tabular}{|c|c|c|c|c|}
\hline $\begin{array}{c}\text { Visual } \\
\text { Acuity }\end{array}$ & $\begin{array}{c}\text { Fre- } \\
\text { quency, } \\
\text { Group I }\end{array}$ & $\begin{array}{c}\text { \% } \\
\text { Group } \\
\mathbf{1}\end{array}$ & $\begin{array}{c}\text { Frequency } \\
\text { Group 2 }\end{array}$ & $\begin{array}{c}\text { \% } \\
\text { Group 2 }\end{array}$ \\
\hline $\begin{array}{c}6 / 6- \\
6 / 9\end{array}$ & 9 & 19.15 & 3 & 11.1 \\
\hline $\begin{array}{c}6 / 9- \\
6 / 12\end{array}$ & 21 & 44.68 & 11 & 40.7 \\
\hline $\begin{array}{c}6 / 18- \\
6 / 24\end{array}$ & 11 & 23.4 & 10 & 37.0 \\
\hline $\begin{array}{c}6 / 36- \\
6 / 60\end{array}$ & 5 & 10.64 & 2 & 7.4 \\
\hline$<6 / 60$ & 1 & 2.13 & 1 & 3.7 \\
\hline Total & 47 & $\mathbf{1 0 0}$ & $\mathbf{2 7}$ & $\mathbf{1 0 0}$ \\
\hline \multicolumn{5}{|c|}{$\begin{array}{c}\text { Table 3: Visual Acuity on Presentation } \\
\text { - Group 1 \& 2 Before Treatment }\end{array}$} \\
\hline \multicolumn{5}{|c|}{}
\end{tabular}




\begin{tabular}{|c|c|c|c|c|}
\hline OCT Patterns & $\begin{array}{c}\text { Frequency } \\
\text { Group I }\end{array}$ & $\begin{array}{c}\text { Percentage } \\
\text { Group I }\end{array}$ & $\begin{array}{c}\text { Frequency } \\
\text { Group 2 }\end{array}$ & $\begin{array}{c}\text { Percentage } \\
\text { Group 2 }\end{array}$ \\
\hline Cystoid macular oedema & 4 & 8.52 & 8 & 29.63 \\
\hline Focal thickening & 21 & 44.68 & 3 & 11.11 \\
\hline Serous detachment & 2 & 4.26 & 3 & 11.11 \\
\hline Spongiform thickening & 14 & 29.78 & 10 & 37.03 \\
\hline Nil & 6 & 12.76 & 3 & 11.11 \\
\hline Total & $\mathbf{4 7}$ & $\mathbf{1 0 0 . 0}$ & $\mathbf{2 7}$ & $\mathbf{1 0 0 . 0}$ \\
\hline
\end{tabular}

\begin{tabular}{|c|c|c|c|c|c|c|}
\hline $\begin{array}{c}\text { Number of } \\
\text { Lines }\end{array}$ & $\begin{array}{c}\text { 4 Weeks, } \\
\text { Group I }\end{array}$ & $\begin{array}{c}\text { 4 Weeks, } \\
\text { Group II }\end{array}$ & $\begin{array}{c}\text { 8 Weeks } \\
\text { Group I }\end{array}$ & $\begin{array}{c}\text { 8 Weeks } \\
\text { Group II }\end{array}$ & $\begin{array}{c}\text { 12 Weeks } \\
\text { Group I }\end{array}$ & $\begin{array}{c}\text { 12 Weeks, } \\
\text { Group II }\end{array}$ \\
\hline Improved & $13(27.7 \%)$ & $5(18.5 \%)$ & $11(23.4 \%)$ & $6(22.22 \%)$ & $9(19.1 \%)$ & $6(22.22 \%)$ \\
\hline Stable & $21(44.7 \%)$ & $13(48.1 \%)$ & $9(19.1 \%)$ & $11(40.74 \%)$ & $7(14.9 \%)$ & $10(37 \%)$ \\
\hline Decreased & $13(27.7 \%)$ & $9(33.3 \%)$ & $27(57.4 \%)$ & $10(37.03 \%)$ & $31(66 \%)$ & $11(40.74 \%)$ \\
\hline \multicolumn{7}{|c|}{ Table 5: Visual Acuity Comparison After Treatment Group 1 \& 2 } \\
\hline
\end{tabular}

\begin{tabular}{|c|c|c|c|c|c|c|c|c|}
\hline CMT & $\begin{array}{c}\text { No } \\
\text { Group I }\end{array}$ & $\begin{array}{c}\text { Minimum } \\
\text { Group I }\end{array}$ & $\begin{array}{c}\text { Maximum } \\
\text { Group I }\end{array}$ & $\begin{array}{c}\text { Mean } \\
\text { Group I }\end{array}$ & $\begin{array}{c}\text { No } \\
\text { Group 2 }\end{array}$ & $\begin{array}{c}\text { Minimum } \\
\text { Group 2 }\end{array}$ & $\begin{array}{c}\text { Maximum } \\
\text { Group 2 }\end{array}$ & $\begin{array}{c}\text { Mean } \\
\text { Group 2 }\end{array}$ \\
\hline $\begin{array}{c}\text { Pre- } \\
\text { treatment }\end{array}$ & 47 & 164 & 477 & 249.34 & 27 & 210 & 739 & 401.85 \\
\hline 4 weeks & 47 & 153 & 386 & 261.57 & 27 & 245 & 569 & 364.81 \\
\hline 8 weeks & 47 & 153 & 417 & 268.57 & 27 & 252 & 540 & 341.98 \\
\hline 12 weeks & 47 & 212 & 414 & 267.94 & 27 & 224 & 510 & 343.96 \\
\hline \multicolumn{7}{|c|}{ Table 6: Analysis of CMT - Group 1 \& 2 Before Treatment } \\
\hline
\end{tabular}

\begin{tabular}{|c|c|c|c|c|}
\hline CMT & $\begin{array}{c}\text { Frequency } \\
\text { Group I }\end{array}$ & $\begin{array}{c}\text { Percentage } \\
\text { Group I }\end{array}$ & $\begin{array}{c}\text { Frequency } \\
\text { Group 2 }\end{array}$ & $\begin{array}{c}\text { Percentage } \\
\text { Group 2 }\end{array}$ \\
\hline Stable & 8 & 17.0 & 2 & 7.4 \\
\hline Increased & 25 & 53.2 & 9 & 33.3 \\
\hline Decreased & 14 & 29.8 & 16 & 59.3 \\
\hline Total & $\mathbf{4 7}$ & $\mathbf{1 0 0 . 0}$ & $\mathbf{1 0 0 . 0}$ \\
\hline \multicolumn{7}{|c}{} \\
\hline
\end{tabular}

\begin{tabular}{|c|c|c|c|c|c|c|c|c|}
\hline TMV & $\begin{array}{c}\text { No } \\
\text { Group I }\end{array}$ & $\begin{array}{c}\text { Minimum } \\
\text { Group I }\end{array}$ & $\begin{array}{c}\text { Maximum } \\
\text { Group I }\end{array}$ & $\begin{array}{c}\text { Mean } \\
\text { Group I }\end{array}$ & $\begin{array}{c}\text { No } \\
\text { Group 2 }\end{array}$ & $\begin{array}{c}\text { Minimum } \\
\text { Group 2 }\end{array}$ & $\begin{array}{c}\text { Maximum } \\
\text { Group 2 }\end{array}$ & $\begin{array}{c}\text { Mean } \\
\text { Group 2 }\end{array}$ \\
\hline Pre-treatment & 47 & 6.6 & 15.0 & 10.11 & 27 & 9.3 & 16.4 & 11.87 \\
\hline 4 weeks & 47 & 6.7 & 13.8 & 9.72 & 27 & 9.3 & 13.9 & 11.26 \\
\hline 8 weeks & 47 & 6.8 & 13.2 & 9.77 & 27 & 9.6 & 13.6 & 11.23 \\
\hline 12 weeks & 47 & 8.6 & 12.9 & 9.81 & 27 & 9.2 & 13.7 & 11.23 \\
\hline \multicolumn{7}{|c|}{ Table 8: Analysis of Total Macular Volume Before Treatment - Group 1 \& 2 } \\
\hline
\end{tabular}

\begin{tabular}{|c|c|c|c|c|}
\hline TMV & $\begin{array}{c}\text { Frequency } \\
\text { Group I }\end{array}$ & $\begin{array}{c}\text { Percentage } \\
\text { Group I }\end{array}$ & $\begin{array}{c}\text { Frequency } \\
\text { Group 2 }\end{array}$ & $\begin{array}{c}\text { Percentage } \\
\text { Group 2 }\end{array}$ \\
\hline Stable & 3 & 6.4 & 2 & 7.4 \\
\hline Increased & 17 & 36.2 & 9 & 33.3 \\
\hline Decreased & 27 & 57.4 & 16 & 59.3 \\
\hline Total & $\mathbf{4 7}$ & $\mathbf{1 0 0 . 0}$ & $\mathbf{2 7}$ & $\mathbf{1 0 0 . 0}$ \\
\hline \multicolumn{4}{|r}{} \\
\hline
\end{tabular}




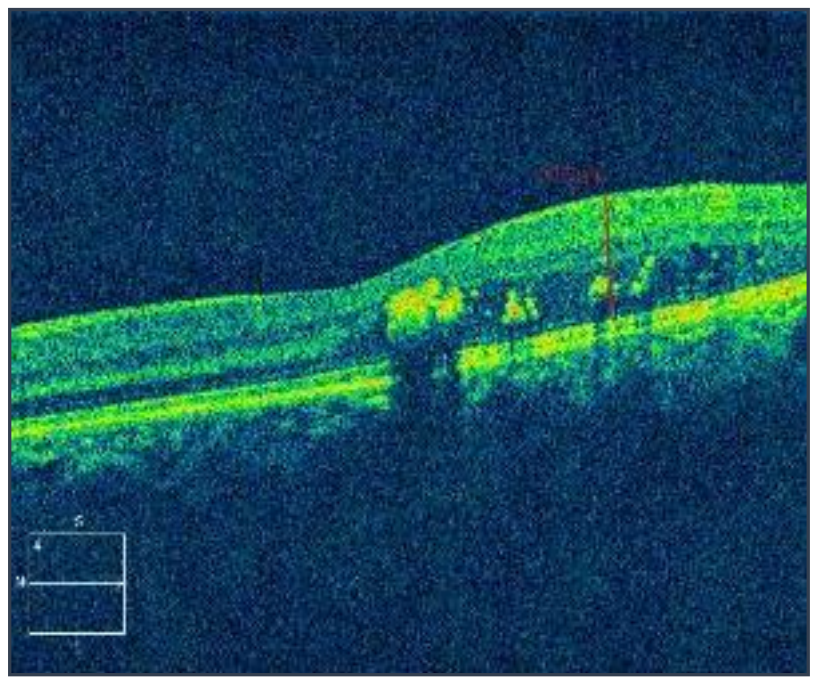

Fig. 1 A: Spongiform Thickening and Hard Exudates Before Laser

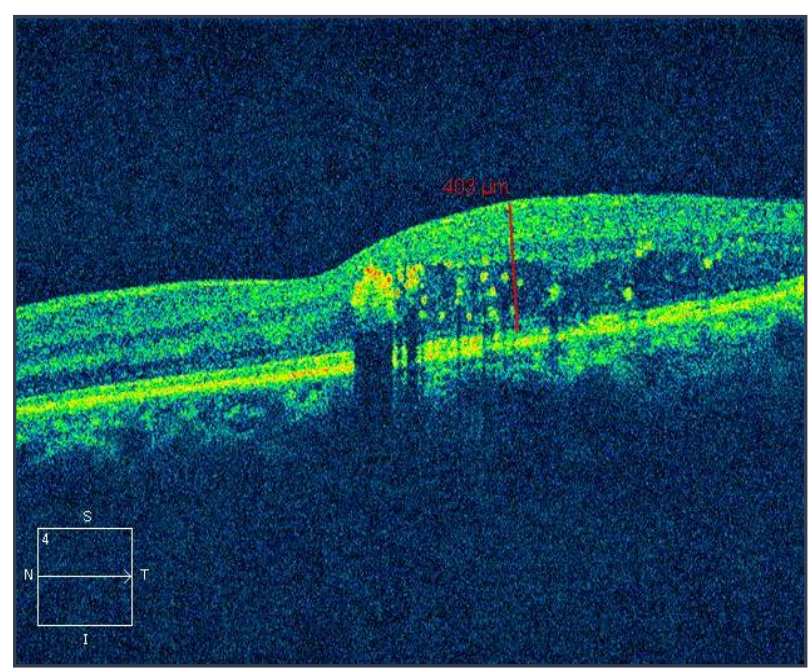

Fig. 1 B: Increase in Macular Thickness One Week After Treatments

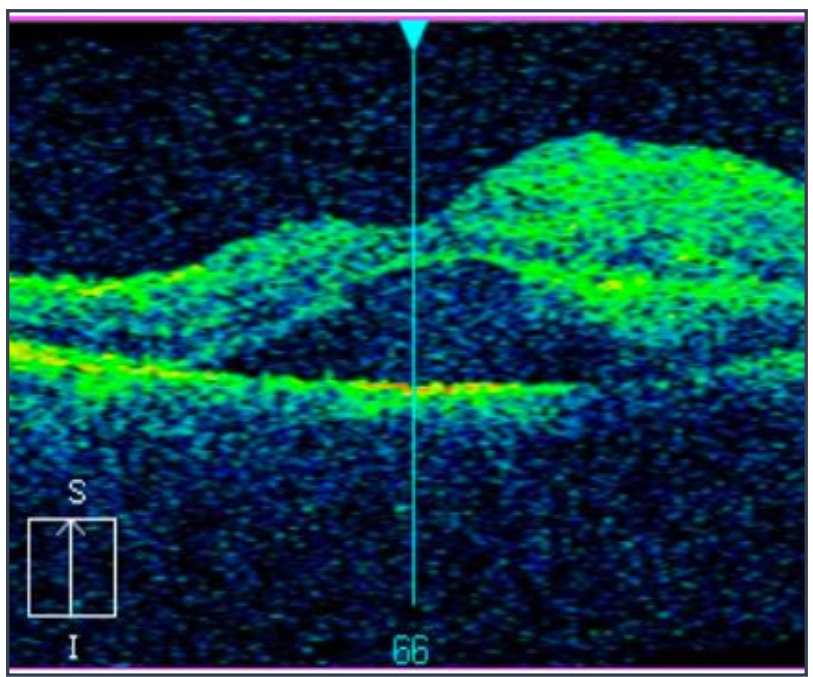

Fig. 2 A: Subretinal Fluid and Spongiform Thickening Before Treatment

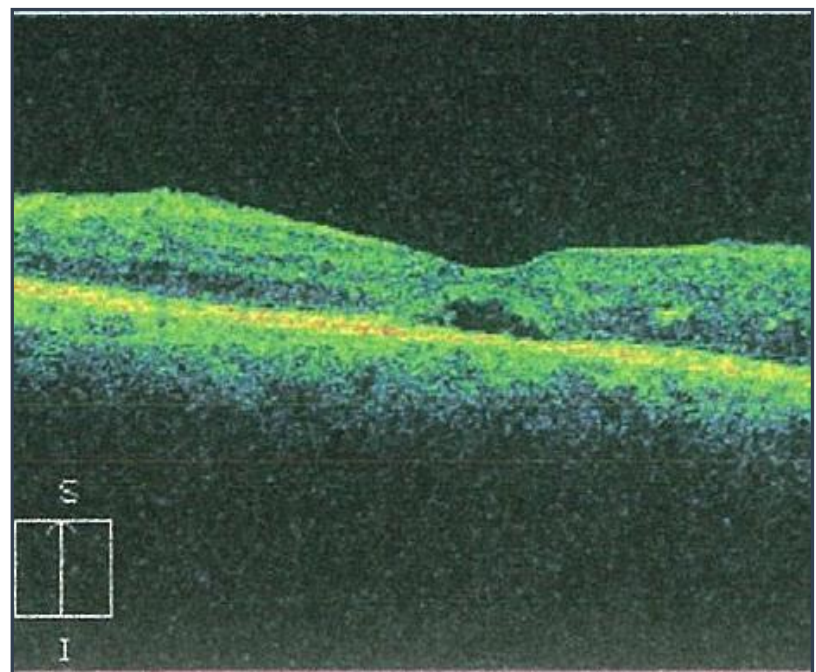

Fig. 2 B: Decrease in Subretinal Fluid and Spongiform Thickening 12 Weeks after Combination Therapy

\section{REFERENCES}

1. Adam S Wenick, Neil M Bressler. Diabetic macular oedema: current and emerging therapies. Middle East Afr J Ophthalmol 2012;19(1):4-12.

2. Klein R, Klein BE, Moss SE. Visual impairment in diabetes. Ophthalmology 1984;91(1):1-9.

3. Early treatment diabetic retinopathy study research group. Early photocoagulation for diabetic retinopathy: ETDRS report number 9. Ophthalmology 1991;98(5):766-85.

4. Coscas G, Cunha-Vaz J, Soubrane G. Macular oedema: definition and basic concepts. Dev Ophthalmol 2010;47:1-9. doi: 10.1159/000320070.

5. Scholl S, Augustin A, Loewenstein A, et al. General pathophysiology of macular oedema. Eur J Ophthalmol 2011;21(6):S10-9. doi: 10.5301/EJ0.2010.6050.

6. Akduman L, Olk RJ. Laser photocoagulation of diabetic macular oedema. Ophthalmic Surg Lasers and Imaging Retina 1997;28(5):387-408.

7. Photocoagulation for diabetic macular oedema early treatment diabetic retinopathy study report number 1 early treatment diabetic retinopathy study research group. Arch Ophthalmol 1985;103(12):1796-806.

8. Aiello LP, Avery RL, Arrigg PG, et al. Vascular endothelial growth factor in ocular fluid of patients with diabetic retinopathy and other retinal disorders. N Engl J Med 1994;331:1480-7.

9. Gardner TW, Antonetti DA, Barber AJ, et al. Diabetic retinopathy: more than meets the eye. Surv Ophthalmol 2002;47(2):S253-62.

10. Cunningham ET Jr, Adamis AP, Altaweel M, et al. A phase II randomized double-masked trial of pegaptanib, an anti-vascular endothelial growth factor aptamer, for diabetic macular oedema. Ophthalmology 2005;112(10):1747-57.

11. Lam DS, Lai TY, Lee VY, et al. Efficacy of $1.25 \mathrm{MG}$ versus 2.5 MG intravitreal bevacizumab for diabetic macular oedema: Six-month results of a randomized controlled trial. Retina 2009;29(3):292-9.

12. Fang X, Sakaguchi H, Gomi F, et al. Efficacy and safety of one intravitreal injection of bevacizumab in diabetic macular oedema. Acta Ophthalmol 2008;86(7):800-5. 
13. Ferrara N. Vascular endothelial growth factor: basic science and clinical progress. Endocr Rev 2004;25(4):581-611.

14. Ferrara N, Hillan KJ, Gerber HP, et al. Discovery and development of bevacizumab, an anti-VEGF antibody for treating cancer. Nat Rev Drug Discov 2004;3(5):391-400.

15. Chen Y, Wiesmann C, Fuh G, et al. Selection and analysis of an optimized anti-VEGF antibody: crystal structure of an affinity-matured fab in complex with antigen. J Mol Biol 1999;293(4):865-81.

16. Ahmadieh H, Ramezani A, Shoeibi N, et al. Intravitreal bevacizumab with or without triamcinolone for refractory diabetic macular oedema; a placebocontrolled, randomized clinical trial. Graefes Arch Clin Exp Ophthalmol 2008;246(4):483-9.

17. Ronald Klein, Klein EK, Scot E Moss, et al. The Wisconsin epidemiologic study of diabetic retinopathy II prevalence and risk of diabetic retinopathy when age at diagnosis is less than 30 years. Arch Ophthalmol 1984;102(4):520-6. doi:10.1001/archopht.1984.01040030398010.

18. Vassiliki Poulaki, Wenying Qin, Antonia M Joussen, et al. Acute intensive insulin therapy exacerbates diabetic blood-retinal barrier breakdown via hypoxia-inducible factor-1 $\alpha$ and VEGF. Clin Invest 2002;109(6):805-15. doi:10.1172/JCI13776.
19. Olk RJ. Modified grid argon laser photocoagulation for diffuse diabetic macular oedema. Ophthalmology 1986;93(7):938-50.

20. Blankenship GW. Diabetic macular oedema and argon laser photocoagulation: a prospective randomized study. Ophthalmology 1979;86(1):69-78.

21. Townsend C, Bailey J, Kohner E. Xenon arc photocoagulation for the treatment of diabetic maculopathy: interim report of a multicenter controlled clinical study. Br J Ophthalmol 1980;64(6):385-91.

22. Haritoglou C, Kook D, Neubauer A, et al. Intravitreal bevazizumab (avastin) therapy for persistent diffuse diabetic macular oedema. Retina 2006;26(9):999-1005.

23. Arevalo JF, Sanchez JG, Wu L, et al. Primary intravitreal bevazizumab for diffuse diabetic macular oedema: the pan- American collaborativ retina study group at 24 months. ophthalmology 2009;116(8):1488-97.

24. Atul Kumar, Subijay Sinha. Intravitreal bevazizumab (avastin) treatment of diffuse diabetic macular oedema in Indian population. IJO 2007;55(6):451-55.

25. Scott IU, Edwards AR. Diabetic retinopathy clinical research network a phase ii randomised clinical trial of intravitreal bevazizumab for diabetic macular oedema. Ophthalmology 2007;114(10):1860-7. 